\title{
Heat capacities of alpha-iron(II) molybdate and iron(II) molybdate-II from 5 to $350 \mathrm{~K}^{a}$
}

\author{
WILLIAM G. LYON $^{b}$ and EDGAR F. WESTRUM, JR. ${ }^{c}$ \\ Department of Chemistry, The University of Michigan, \\ Ann Arbor, Michigan 48104, U.S.A.
}

(Received 16 December 1974; in revised form 3 February 1975)

\begin{abstract}
Heat capacities of iron(II) molybdate-II (a metastable high-pressure phase) and of two samples of alpha-iron(II) molybdate were measured over the temperature range 5 to $350 \mathrm{~K}$ by means of adiabatic calorimetry. Rounding of lambda anomalies found at $(43.0 \pm 0.1) \mathrm{K}$ for $\mathrm{FeMoO}_{4}-\mathrm{II}$ and at $(31.5 \pm 0.1) \mathrm{K}$ and $(31.75 \pm 0.1) \mathrm{K}$ for two different samples of $\alpha-\mathrm{FeMoO}_{4}$ is attributed to impurity introduced by hitherto unreported slow air oxidation of these substances. Excess entropies associated with magnetic ordering were estimated as $1.11 \mathrm{cal}_{\mathrm{th}} \mathrm{K}^{-1} \mathrm{~mol}^{-1}$ for $\mathrm{FeMoO}_{4}-\mathrm{II}$ and 1.77 and $1.63 \mathrm{cal}_{\mathrm{th}} \mathrm{K}^{-1} \mathrm{~mol}^{-1}$ for the two samples of $\alpha-\mathrm{FeMoO}_{4}$. At $298.15 \mathrm{~K}$, the values of $C_{p}^{\circ}, S^{\circ},\left\{H^{\circ}(T)-H^{\circ}(0)\right\}$, and $-\left\{G^{\circ}(T)-H^{\circ}(0)\right\} / T$, respectively, are $29.05 \mathrm{cal}_{\mathrm{th}} \mathrm{K}^{-1} \mathrm{~mol}^{-1}, 30.93 \mathrm{cal}_{\mathrm{th}} \mathrm{K}^{-1} \mathrm{~mol}^{-1}$, $4852.3 \mathrm{cal}_{\text {th }} \mathrm{mol}^{-1}$, and $14.656 \mathrm{cal}_{\text {th }} \mathrm{K}^{-1} \mathrm{~mol}^{-1}$ for $\mathrm{FeMoO}_{4}-\mathrm{II}$, and $28.31 \mathrm{cal}_{\mathrm{ln}} \mathrm{K}^{-1} \mathrm{~mol}^{-1}$, $32.7 \mathrm{cal}_{\mathrm{th}} \mathrm{K}^{-1} \mathrm{~mol}^{-1}, 4963 \mathrm{cal}_{\mathrm{th}} \mathrm{mol}^{-1}$, and $16.1 \mathrm{cal}_{\mathrm{th}} \mathrm{K}^{-1} \mathrm{~mol}^{-1}$ (selected composite values) for $\alpha-\mathrm{FeMoO}_{4}$.
\end{abstract}

\section{Introduction}

The solid-state physical and chemical properties of the simple $\mathrm{AMoO}_{4}$ molybdates have recently become important. Of current practical interest is their role in the oxidation of molybdenum alloys $\left(c f\right.$. Brenner $^{(1)}$ and Rahmel et al. $\left.{ }^{(2)}\right)$, their possible use as host-lattices for paramagnetic ions ( $c f$. Van Uitert et al. ${ }^{(3)}$ ), and their possible formation from high-yield fission products in nuclear fuel cells. Unlike the tungstates, the molybdates have few representatives as naturally occurring minerals; moreover, the most prominent of the naturally occurring molybdates, $\mathrm{CaMoO}_{4}$ (powellite) and $\mathrm{PbMoO}_{4}$ (wulfenite), are secondary minerals (cf. Palache et al. ${ }^{(4)}$ ). The fact that the primary mineral of molybdenum is the disulfide $\operatorname{MoS}_{2}$, rather than a molybdate, has been convincingly rationalized by Urosov et al. ${ }^{(5)}$ on the basis of the thermochemical calculations for systems involving sulfides, tungstates, and molybdates. The considerable difference in geochemical behavior between tungsten

${ }^{a}$ This work was supported in part by the Division of Research of the U.S. Atomic Energy Commission (AEC Cryogenics Project AT(11-1)-1149), and in recent months by the National Science Foundation (Project NSF GP-33424X).

- Abstracted in part from a dissertation submitted in partial fulfiliment of the requirements for the Ph.D. degree from the Horace H. Rackham School of Graduate Studies at The University of Michigan. Present address: Chemistry Division, Argonne National Laboratory, Argonne, Illinois 60439 , U.S.A.

$c$ To whom correspondence concerning this paper should be directed. 
and molybdenum indicates fundamental differences in the crystal chemistry and thermodynamics of tungstates and molybdates. To the understanding of this, accurate thermochemical and thermophysical studies can contribute.

The crystal chemistry of the $\mathrm{AMoO}_{4}$ molybdates as a function of temperature and pressure has been recently reviewed by Sleight and Chamberland $;^{(6)}$ the reader is referred to that review for a full discussion of their rather complex structures and their relationships to one another. The structure of $\alpha-\mathrm{FeMoO}_{4}$ has been found by Sleight et al. ${ }^{(7)}$ to be of the $\alpha-\mathrm{CoMoO}_{4}$-type described by Smith and Ibers. ${ }^{(8)}$ Although the studies of Young and Schwartz ${ }^{(9)}$ and of Marshall ${ }^{(10)}$ were apparently consistent with the monoclinic symmetry expected for $\mathrm{FeMoO}_{4}$-II (high-pressure phase) having a structure of the $\mathrm{NiWO}_{4}$-type described by Keeling, ${ }^{(11)}$ the subsequent single-crystal studies of Sleight et al. ${ }^{(7)}$ showed the structure to be a triclinic variant of the $\mathrm{NiWO}_{4}$-type.

The previous heat-capacity study of $\alpha-\mathrm{FeMoO}$ fiom 50 to $300 \mathrm{~K}$ by Weller ${ }^{(12)}$ ignored the possibility of a magnetic transition below $50 \mathrm{~K}$; hence, the thermal functions predicated upon a smooth extrapolation to $\tau=0$ were likely to be significantly inaccurate. The magnetic-susceptibility studies of Sleight et al. ${ }^{(7)}$ (indicative of magnetic ordering in $\alpha-\mathrm{FeMoO}_{4}$ and $\mathrm{FeMoO}_{4}$-II near 30 and $45 \mathrm{~K}$, respectively) motivated low-temperature heat-capacity investigation of both materials over the 5 to $350 \mathrm{~K}$ range. These results permit a comparison of magnetic heat capacities not only between the two structures of iron(II) molybdate, but also between FeMoO $4-\mathrm{II}$ and the closely related $\mathrm{FeWO}_{4}\left(c f\right.$. Lyon and Westrum $\left.{ }^{(13)}\right)$.

\section{Experimental}

\section{SAMPLE CIIARACTERIZATION}

$\mathrm{FeMoO}_{4}$-II

Dr A. W. Sleight prepared the sample of $\mathrm{FeMoO}_{4} \mathrm{II}$ used in this research using hydrothermal methods described by Sleight et al. ${ }^{(7)}$ However, the synthesis was scaled up about thirty-fold to provide a sample of sufficient mass for the calorimetric measurements. Debye-Scherrer X-ray photographs $(\mathrm{Cu} \mathrm{K} \alpha)$ made by Dr Sleight for the freshly prepared sample indicated no impurity lines from $\alpha-\mathrm{Fe}_{2} \mathrm{O}_{3}, \mathrm{MoO}_{3}$, or $\mathrm{Fe}_{2}\left(\mathrm{MoO}_{4}\right)_{3}$. Unfortunately, the ready oxidizability of this material was unanticipated, and the calorimetric sample was stored exposed to air for several months prior to the heat-capacity measurements.

Further X-ray work (Guinier, $\mathrm{Cu} \mathrm{K} \alpha$ ) was done after completion of the calorimetric measurements, because the rounded nature of the antiferromagnetic anomaly seemed an indication that the sample might have been contaminated. A complete tabulation of the measured $d$-spacings for this sample has been reported previously ${ }^{114)}$ and is also available as a supplementary document. ${ }^{(15)}$ The triclinic lattice parameters obtained for this material in this research revealed no significant systematic deviations relative to the parameters determined by Sleight et al. ${ }^{(7)}$ indicative of distortions due to solid solution of impurities; a comparison of parameters is given in table 1.

Several distinct impurity lines were observed in the powder pattern for this 
TABLE 1. Comparison of iron(II) molybdate-II lattice parameters for triclinic cell ${ }^{a}$

\begin{tabular}{|c|c|c|c|c|c|c|}
\hline$\frac{a}{\mathrm{~nm}}$ & $\frac{b}{\mathrm{~nm}}$ & $\frac{c}{\mathrm{~nm}}$ & $\alpha$ & $\beta$ & $\gamma$ & Reference \\
\hline 0.462 & 0.562 & 0.490 & - & $90^{\circ b}$ & - & $\begin{array}{l}\text { Young and } \\
\text { Schwartz }^{(9)}\end{array}$ \\
\hline 0.469 & 0.569 & 0.494 & - & $90.25^{\circ b}$ & - & Marshall $^{(10)}$ \\
\hline 0.47078 & 0.57006 & 0.49443 & $90.67^{\circ}$ & $90.27^{\circ}$ & $87.68^{\circ}$ & $\begin{array}{l}\text { Sleight } \\
\text { et al. }{ }^{(7)}\end{array}$ \\
\hline \multicolumn{7}{|c|}{$(4.708 \pm 0.009)(5.703 \pm 0.012)(4.936 \pm 0.009)(90.62 \pm 0.15)^{\circ}(90.20 \pm 0.22)^{\circ}(87.73 \pm 0.20)^{\circ}$ This $_{\text {research }}{ }^{e}$} \\
\hline
\end{tabular}

a All parameters based on $\mathrm{NiWO}_{4}$-type cell.

${ }^{b}$ Cell thought to be monoclinic.

- Guinier, $\mathrm{Cu} \mathrm{K} \alpha_{1}$ using $\alpha$-Si as an internal standard. Parameters are based on a least-squares fit of 33 indexed lines. Uncertainties are given as three standard deviations.

$\mathrm{FeMoO}_{4}$-II sample. These have been determined to coincide with the strong lines corresponding to $\alpha-\mathrm{Fe}_{2} \mathrm{O}_{3}$ (hematite). A sufficient number of such lines were present so that a set of lattice parameters (hexagonal) for the $\alpha-\mathrm{Fe}_{2} \mathrm{O}_{3}$ impurity could be derived $[a=(0.5034 \pm 0.0009) \mathrm{nm} ; c=(1.379 \pm 0.003) \mathrm{nm}]$. The parameters given in the Powder Diffraction File ${ }^{(16)}$ for a known pure $\alpha-\mathrm{Fe}_{2} \mathrm{O}_{3}(a=0.50317 \mathrm{~nm}$; $c=1.3737 \mathrm{~nm}$ ) differ only in the slightly smaller value for $c$; whether this slight difference mighi be due to traces of molybdenum in the $\alpha-\mathrm{Fe}_{2} \mathrm{O}_{3}$ impurity is a moot point. No impurity lines were found corresponding to $\mathrm{MoO}_{3}, \alpha-\mathrm{FeMoO}_{4}$, or $\mathrm{Fe}_{2}\left(\mathrm{MoO}_{4}\right)_{3}$.

In contrast to the above, Dr Sleight ${ }^{(17)}$ has determined that initially clean samples of $\mathrm{FeMoO}_{4}$-II stored at his laboratory for several years now show lines for $\alpha-\mathrm{Fe}_{2} \mathrm{O}_{3}$, $\alpha-\mathrm{FeMoO}_{4}$, and $\mathrm{Fe}_{2}\left(\mathrm{MoO}_{4}\right)_{3}$ in the powder pattern (Guinier, $\mathrm{Cr} \mathrm{K \alpha}$ ). The presence of traces of $\alpha-\mathrm{FeMoO}_{4}$ in aged samples of $\mathrm{FeMoO}_{4}-\mathrm{II}$ provides confirmation of the conclusion of Sleight et al. ${ }^{(7)}$ that $\alpha-\mathrm{FeMoO}_{4}$ is the thermodynamically stable phase of ferrous molybdate at $298.15 \mathrm{~K}$ and $1 \mathrm{~atm} . \dot{\mathrm{f}}$

Chemical analyses of the $\mathrm{FeMoO}_{4}$-II sample for total iron and molybdenum are presented in table 2. Due to the mutual interference of iron and molybdenum in the analyses, and the necessity of an initial separation, the mole ratio $\{n(\mathrm{Fe}) / n(\mathrm{Mo})\}$ is considered more reliably determined than the absolute percentages of $\mathrm{Fe}$ and Mo. Oxidative thermogravimetric analysis of $\mathrm{FeMoO}_{4} \mathrm{-II}$ at this laboratory yielded a mass fraction of 0.7682 for $\mathrm{FeMoO}_{4}$, corresponding to 25.67 mass per cent $\mathrm{Fe}$ (assuming an initial mole ratio $\{n(\mathrm{Fe}) / n(\mathrm{Mo})\}$ of unity). Since this latter analysis was performed considerably later (January 1974) than the heat-capacity measurements, the value 0.7682 is taken as a lower bound on the phase purity of the calorimetric sample.

In addition to the solid-phase contaminants, the sample was determined (by calorimetric means) to contain 0.0202 mass per cent of $\mathrm{H}_{2} \mathrm{O}$. Further details of this determination are postponed until after the presentation of calorimetric results.

$\dagger$ Through this paper $\mathrm{cal}_{t \mathrm{~h}}=4.184 \mathrm{~J}$; atm $=101.325 \mathrm{kPa}$; Torr $=(101.325 / 760) \mathrm{kPa}$. 
W. G. LYON AND E. F. WESTRUM, JR.

TABLE 2. Chemical analyses of iron(II) molybdates ${ }^{a}, w(\mathrm{Fe})$ and $w(\mathrm{Mo})$ are the mass fractions of $\mathrm{Fe}$ and Mo respectively, and $\{n(\mathrm{Fe}) / n(\mathrm{Mo})\}$ is the mole ratio of $\mathrm{Fe}$ and Mo

\begin{tabular}{|c|c|c|c|}
\hline Sample & $10^{2} w(\mathrm{Fe})$ & $10^{2} w(\mathrm{Mo})$ & $n(\mathrm{Fe}) / n(\mathrm{Mo})$ \\
\hline \multirow[t]{2}{*}{$\mathrm{FeMoO}_{4}-\mathrm{II}$} & $25.79^{b}$ & $43.71^{d}$ & 1.014 \\
\hline & $25.75^{c}$ & $43.65^{d}$ & 1.013 \\
\hline$\alpha-\mathrm{FeMoO}_{4}$ & $25.03^{b}$ & $42.87^{d}$ & 1.003 \\
\hline (Dupont) & $24.74^{\circ}$ & $42.44^{e}$ & 1.001 \\
\hline$\alpha-\mathrm{FeMoO}_{1}$ & $25.02^{b}$ & $42.72^{d}$ & \\
\hline (Bureau of Mines) & $24.60^{c}$ & $42.62^{d}$ & $0.999 f . g$ \\
\hline $\mathrm{FeMoO}_{4}$ (Theory) & 25.88 & 44.46 & 1.000 \\
\hline$\left\{2 \mathrm{Fe}_{2} \mathrm{O}_{3}+4 \mathrm{MoO}_{3}\right\}$ (Theory) & 24.96 & 42.87 & 1.000 \\
\hline
\end{tabular}

${ }^{a}$ Schwarzkopf Microanalytical Laboratory, Woodside, New York, February 1974.

${ }^{b}$ Titration with $\mathrm{K}_{2} \mathrm{Cr}_{2} \mathrm{O}_{7}$.

- Specific colorimetry.

a Precipitation as $\mathrm{PbMoO}_{4}$ after extraction of $\mathrm{Fe}$ as phenanthroline complex.

- Atomic absorption spectroscopy after extraction of $\mathrm{Fe}$ as phenanthroline complex.

${ }^{f}$ This is an average value. Analyses for $\mathrm{Fe}$ and Mo were uncorrelated for this sample.

$g$ Weller's analytical results ${ }^{(12)}$ yielded 25.91 mass per cent $\mathrm{Fe}, 44.44$ mass per cent $\mathrm{Mo}$, and a mole ratio of 1.002 .

\section{$\alpha-\mathrm{FeMoO}_{4}$}

Two samples of $\alpha-\mathrm{FeMoO}_{4}$ were used in this research. The first of these was the calorimetric sample used by Wcller ${ }^{(12)}$ for his heat-capacity measurements in the 50 to $300 \mathrm{~K}$ range. In subsequent discussion, this sample will be denoted the "Bureau of Mines" sample. The second sample of $\alpha-\mathrm{FeMoO}_{4}$ (the "Dupont sample") was prepared by Dr A. W. Sleight according to methods described by Sleight et ll $^{(7)}$ scaled up to produce a calorimetric sample of sufficient mass.

Debye-Scherrer photographs of the fresh samples showed no extra lines for oxides of iron or molybdenum for either sample. Since at the time the original X-ray work was done on the Bureau of Mines sample ( $c f$. Weller ${ }^{(12)}$ ) there were no data on pure $\alpha-\mathrm{FeMoO}_{4}$ available for comparison, it is possible that a contaminant such as $\mathrm{Fe}_{2}\left(\mathrm{MoO}_{4}\right)_{3}$ might have escaped detection in this sample. Both samples were stored exposed to air prior to the calorimetric measurements. For the Bureau of Mines sample, this exposure was many times greater; the sample had been evidently stored in contact with air ever since the measurements by Weller were completed.

Following the heat-capacity measurements of the present research, further X-ray powder patterns (Guinier, $\mathrm{Cu} \mathrm{K} \alpha$ ) were made for both samples. As in the case of $\mathrm{FeMoO}_{4}-\mathrm{II}$, the roundedness of the transitions seemed an indication of possible sample contamination. The measured $d$-spacings were reported previously by Lyon $^{(14)}$ and are also available in a supplementary document. ${ }^{(15)}$ These results give definite indications of contamination of both samples by $\alpha-\mathrm{Fe}_{2} \mathrm{O}_{3}, \mathrm{MoO}_{3}$, and $\mathrm{Fe}_{2}\left(\mathrm{MoO}_{4}\right)_{3}$. Two structures have been reported for $\mathrm{Fe}_{2}\left(\mathrm{MoO}_{4}\right)_{3}$. Nassau et al. ${ }^{(18)}$ and Trunov and Kovba ${ }^{(19)}$ have given parameters for an orthorhombic variety of this material; whereas, Plyasova et al., ${ }^{(20)}$ Klevtsov et al., ${ }^{(21)}$ Marshall, ${ }^{(10)}$ and Sleight and Brixner ${ }^{(22)}$ have investigated a monoclinic form. Kozmanov ${ }^{(23)}$ and Jäger et al. ${ }^{(24)}$ have reported powder patterns for $\mathrm{Fe}_{2}\left(\mathrm{MoO}_{4}\right)_{3}$ which neither agree 
with each other nor may be convincingly indexed with the orthorhombic or monoclinic cell parameters. Sleight and Brixner ${ }^{(22)}$ have concluded that the monoclinic phase is the stable phase at $298.15 \mathrm{~K}$, but have found a sluggish diffusive transition near $772 \mathrm{~K}$ which may account for some of the discrepancies in the reported results. The present research indicates a separate phase (or phases) which correspond most closely with the pattern given by Kozmanov. ${ }^{(23)}$ Additional impurity lines in $\alpha-\mathrm{FeMoO}{ }_{4}$ were present which could not be indexed at all; however, many of these were probably weaker lines of the $\mathrm{Fe}_{2}\left(\mathrm{MoO}_{4}\right)_{3}$ phase(s) which were not observed or not reported by Kozmanov. ${ }^{(23)}$

Dr Sleight ${ }^{(17)}$ has revealed that similar oxidation has occurred in initially uncontaminated samples of $\alpha-\mathrm{FeMoO}_{4}$ which had been stored for several years at his laboratory; X-ray powder patterns (Guinier, $\mathrm{Cr} \mathrm{K} \alpha$ ) showed extra lines for $\alpha-\mathrm{Fe}_{2} \mathrm{O}_{3}$ and $\mathrm{Fe}_{2}\left(\mathrm{MoO}_{4}\right)_{3}$. In contrast to the work on the calorimetric sample, however, no lines for $\mathrm{MoO}_{3}$ were found.

Lattice parameters derived from the lines measured in this research for the two samples of $\alpha-\mathrm{FeMoO}_{4}$ are presented in table 3 . In both cases, the lattice parameters

TABLE 3. Derived lattice parameters of $\alpha$-ferrous molybdate ${ }^{a}$

\begin{tabular}{|c|c|c|c|c|}
\hline Sample & $a / \mathrm{nm}$ & $b / \mathrm{nm}$ & $c / \mathrm{nm}$ & $\beta$ \\
\hline Sleight et al..$^{(7)}$ & 0.9805 & 0.8950 & 0.7660 & $114.05^{\circ}$ \\
\hline Dupont ${ }^{\circ}$ & $0.980 \pm 0.001$ & $0.895 \pm 0.001$ & $0.766 \pm 0.001$ & $(114.05 \pm 0.09)^{\circ}$ \\
\hline Bureau of Mines ${ }^{c}$ & $0.979 \pm 0.002$ & $0.895 \pm 0.002$ & $0.765 \pm 0.001$ & $(114.0 \pm 0.1)^{\circ}$ \\
\hline
\end{tabular}

a The uncertainties are three times the standard deviations from the least-squares fit of the measured lines.

${ }^{\circ}$ Parameters based on least-squares fitting of 24 lines.

c Parameters based on least-squares fitting of 28 lines.

are in close agreement with those determined by Sleight et al. ${ }^{(7)}$ Hence, despite suspicions concerning the purity of the predominant $\alpha-\mathrm{FeMoO}$ phase, firm evidence for contamination of this phase (i.e. evidence indicative of solid solution) was not obtained from the powder patterns. Nevertheless, the conclusion that the Dupont sample is the better sample can be supported by the fact that the powder pattern for this sample showed fewer impurity lines and had generally sharper lines for the $\alpha-\mathrm{FeMoO}_{4}$ phase.

Results of chemical analysis are presented in table 2 for both samples of $\alpha-\mathrm{FeMoO}_{4}$. No significant difference between samples is evident from these results, even though there is a considerable difference in color between the two; the Bureau of Mines sample had a slate-grey color, while the Dupont sample was black. As in the case of $\mathrm{FeMoO}_{4}$-II, the mutual interference of $\mathrm{Fe}$ and $\mathrm{Mo}$, render the absolute percentages of $\mathrm{Fe}$ and $\mathrm{Mo}$ somewhat suspect; the mole ratio is considered more reliably determined.

Oxidative thermogravimetric analysis of the $\alpha-\mathrm{FeMoO}_{4}$ samples conducted at this laboratory did not yield unambiguous results. Both samples, when heated in oxygen, undergo a mass loss (greater for the Bureau of Mines sample) just prior to 
(and overlapping) mass gain from oxidation. The mass loss in both cases is believed due to the volatilization of free $\mathrm{MoO}_{3}$; in the case of the Bureau of Mines sample, separate mass loss determinations in nitrogen indicate a loss of 0.48 per cent. However, the temperature at which mass loss occurs in $\mathrm{N}_{2}$ is so much lower than in $\mathrm{O}_{2}$ that it appears very dubious whether the identical process is occurring in each case. Indeed, calculations attempting to correct for mass loss as $\mathrm{MoO}_{3}$ give results clearly at variance with the chemical analyses of table 2 . From the t.g.a. results it was concluded not only that the samples of $\alpha-\mathrm{FeMoO}_{4}$ are less pure than the sample of $\mathrm{FeMoO}_{4}$-II, but also that the mass fraction of $\mathrm{FeMoO}_{4}$ is in each case larger than 0.7 .

\section{HEAT CAPACITY MEASUREMENTS}

Loading details and results. Heat capacity measurements for all three samples were made in the Mark II adiabatic cryostat. ${ }^{(25)}$ Loading information for these samples is given in table 4. Heat capacities (or enthalpy increments) given in tables 5 through 7

TABLE 4. Calorimeter loading information: $m$ is mass of sample and $p$ the pressure of He added

$$
(\text { Torr }=(101.325 / 760) \mathrm{kPa})
$$

\begin{tabular}{|c|c|c|c|c|}
\hline \multicolumn{5}{|c|}{ Mark-II Cryostat (A-5 Thermometer) ${ }^{a}$} \\
\hline Compound & Sample & Calorimeter $^{b}$ & $m / g^{c}$ & $p$ : Torr $^{a}$ \\
\hline$\alpha-\mathrm{FeMoO} 4$ & Dupont ${ }^{e}$ & $\mathrm{~W}-39\left(23 \mathrm{~cm}^{3}\right)$ & 34.7332 & 52 \\
\hline$\alpha-\mathrm{FeMoO}_{4}$ & Bureau of Mines $f$ & W-42 $\left(93 \mathrm{~cm}^{3}\right)$ & 168.7785 & 86 \\
\hline $\mathrm{FeMoO}_{4}-\mathrm{II}$ & Dupont ${ }^{g}$ & $\mathrm{~W}-39\left(23 \mathrm{~cm}^{3}\right)$ & $\begin{array}{c}58.3746 \\
(58.3630)\end{array}$ & 90 \\
\hline
\end{tabular}

a Westrum et al. ${ }^{(25)}$.

bold-plated copper calorimeters, laboratory designations.

c Densities of 4.668 and $5.425 \mathrm{~g} \mathrm{~cm}^{-3}$ were used for the buoyancy corrections for $\alpha$-FeMoO samples and for $\mathrm{FeMoO}_{4} \mathrm{II}$, respectively. [Cf. Sleight et al. $\left.{ }^{(7)}\right]$

${ }^{d}$ Helium gas added to calorimeter to enhance thermal contact between sample and calorimeterthermometer-heater assembly.

e Sample loaded December 1968.

$f$ Sample loaded May 1969. Prior to loading, this sample was heated in vacuum to $600 \mathrm{~K}$ for $1 \mathrm{hr}$, during which time considerable outgassing occurred.

g Sample loaded June 1969.

$h$ The sample mass less that of the separate phase $\mathrm{H}_{2} \mathrm{O}$ is given in parentheses.

are expressed in terms of a molar mass of $215.7846 \mathrm{~g} \mathrm{~mol}^{-1}$. Approximate temperature increments can usually be deduced from adjacent mean temperatures. Molar heatcapacity curves for $\mathrm{FeMoO}_{4}-\mathrm{II}$ and $\alpha-\mathrm{FeMoO}_{4}$ are displayed in figures 1 and 2, respectively.

Heat capacity of $\mathrm{FeMoO}_{4}$-II. The major feature of the heat capacity of $\mathrm{FeMoO}_{4}-\mathrm{II}$ is a rounded bump whose maximum in the total heat capacity is located at $(43.0 \pm 0.1) \mathrm{K}$. Since the anomaly is a rounded one, the temperature of the maximum in the magnetic (excess) heat capacity need not be identical, but may vary somewhat, depending on the choice of lattice heat capacity. 
TABLE 5. Experimental heat capacity of iron(II) molybdate-II ${ }^{a}$

$$
\left(\mathrm{cal}_{\text {th }}=4.184 \mathrm{~J}\right)
$$

\begin{tabular}{|c|c|c|c|c|c|c|c|}
\hline$\frac{T}{\mathrm{~K}}$ & $\frac{C_{p}}{\mathrm{cal}_{\mathrm{th}} \mathrm{K}^{-1} \mathrm{~mol}^{-1}}$ & $\frac{T}{\mathrm{~K}}$ & $\frac{C_{y}}{\mathrm{cal}_{\mathrm{tn}} \mathrm{K}^{-1} \mathrm{~mol}^{-1}}$ & $\frac{T}{\mathrm{~K}}$ & $\frac{C_{p}}{\mathrm{cal}_{\mathrm{th}} \mathrm{K}^{-1}} \frac{\mathrm{mol}^{-1}}{}$ & $\frac{T}{\mathrm{~K}}$ & $\frac{C_{p}}{\mathrm{cal}_{\mathrm{th}} \mathrm{K}^{-1} \mathrm{~mol}^{-1}}$ \\
\hline \multicolumn{2}{|c|}{ Series I } & \multicolumn{2}{|r|}{ Series V } & 124.28 & 14.71 & 9.81 & 0.162 \\
\hline 158.76 & 18.85 & 52.27 & 5.691 & 132.19 & 15.70 & 10.92 & 0.208 \\
\hline 164.46 & 19.40 & 56.73 & 5.651 & 140.40 & 16.72 & 12.21 & 0.253 \\
\hline \multirow[t]{3}{*}{170.01} & 20.01 & 63.12 & 6.201 & & & 13.56 & 0.334 \\
\hline & & 71.36 & 7.206 & \multicolumn{2}{|c|}{ Series IX } & 14.91 & 0.433 \\
\hline \multirow{2}{*}{\multicolumn{2}{|c|}{ Series II }} & 80.05 & 8.460 & $136.03^{2}$ & 16.17 & 16.23 & 0.532 \\
\hline & & 87.00 & 9.515 & $\begin{array}{l}130.03 \\
144.18\end{array}$ & $\begin{array}{l}10.17 \\
17.14\end{array}$ & 17.78 & 0.665 \\
\hline 178.37 & 20.84 & 92.77 & 10.34 & 156.49 & 18.56 & 19.59 & 0.849 \\
\hline 184.51 & 21.52 & & & 164.66 & 19.43 & 21.52 & 1.078 \\
\hline 190.89 & 21.98 & \multirow{2}{*}{\multicolumn{2}{|c|}{ Series VI }} & 172.79 & 20.27 & 23.82 & 1.397 \\
\hline 197.32 & 22.53 & & & 180.83 & 21.04 & 26.46 & 1.826 \\
\hline \multirow[t]{4}{*}{203.70} & 23.03 & 96.73 & $\begin{array}{l}10.91 \\
1167\end{array}$ & 188.74 & 21.75 & 29.11 & 2.337 \\
\hline & & 102.22 & 11.67 & & & 31.89 & 2.978 \\
\hline & & 107.73 & 12.50 & & & 34.72 & $3.812^{b}$ \\
\hline & Series III & 113.15 & 13.21 & & Series X & 37.22 & $4.761^{b}$ \\
\hline 216.43 & 23.96 & 118.62 & 13.94 & 191.56 & 21.97 & 40.06 & $6.101^{b}$ \\
\hline 222.81 & 24.65 & 124.16 & 14.65 & 201.28 & 22.82 & 44.28 & $6.729^{\circ}$ \\
\hline 229.27 & 25.07 & 129.68 & 15.39 & 211.06 & 23.63 & \multirow{2}{*}{\multicolumn{2}{|c|}{ Series XII ${ }^{a}$}} \\
\hline 235.71 & 25.38 & 135.26 & 16.08 & 221.00 & 24.40 & & \\
\hline 242.14 & 26.05 & 140.96 & 16.73 & 231.09 & 25.18 & 43.65 & 6.795 \\
\hline 248.57 & 26.30 & & & 241.36 & 25.86 & 47.54 & 6.242 \\
\hline 254.99 & 26.79 & \multicolumn{2}{|c|}{ Series VII } & 251.82 & 26.49 & 51.54 & 5.702 \\
\hline 261.42 & 27.11 & 62.54 & series vil & 262.46 & 27.17 & 55.56 & 5.600 \\
\hline 267.81 & 27.56 & 68.41 & $\begin{array}{l}0.148 \\
6.817\end{array}$ & $273.20^{a}$ & & 59.44 & 5.738 \\
\hline $274.13^{a}$ & & $\begin{array}{l}0.41 \\
73.98\end{array}$ & $\begin{array}{l}6.811 \\
7.566\end{array}$ & 284.02 & 28.39 & 63.59 & 6.243 \\
\hline \multirow[t]{4}{*}{280.42} & 28.33 & 79.42 & $\begin{array}{l}8.300 \\
8.355\end{array}$ & 294.96 & 28.92 & 68.17 & 6.780 \\
\hline & & 84.66 & 9.162 & $\begin{array}{l}305.98 \\
324.08\end{array}$ & 29.49 & \multirow{2}{*}{\multicolumn{2}{|c|}{ Series XIII ${ }^{b}$}} \\
\hline & \multirow{2}{*}{ Series IV } & 89.75 & 9.893 & $\begin{array}{l}324.08 \\
335.22\end{array}$ & 30.17 & & \\
\hline & & & & & 30.64 & 33.11 & 3.323 \\
\hline 292.71 & 28.97 & & & 343.94 & 30.97 & 35.95 & 4.253 \\
\hline 298.98 & 29.36 & \multicolumn{2}{|r|}{ Series VIII } & 349.67 & 31.16 & 38.33 & 5.228 \\
\hline 305.27 & 29.68 & 78.53 & 8.224 & & & 39.86 & 6.048 \\
\hline 311.51 & 29.78 & 83.59 & 8.999 & & Series XI & 41.01 & 6.529 \\
\hline 317.76 & 30.03 & 89.00 & 9.812 & 5.20 & 0.016 & 42.10 & 6.798 \\
\hline 324.03 & 29.92 & 95.63 & 10.75 & 5.62 & 0.040 & 43.15 & 6.873 \\
\hline 330.24 & 30.67 & 102.78 & 11.76 & 6.56 & 0.025 & 45.20 & 6.660 \\
\hline 336.49 & 30.16 & 109.83 & 12.74 & 7.57 & 0.018 & 48.32 & 6.107 \\
\hline 343.60 & 30.98 & 116.98 & 13.71 & 8.72 & 0.122 & 51.95 & 5.676 \\
\hline
\end{tabular}

${ }^{a}$ Water fusion anomaly.

${ }^{b}$ No correction for curvature.

In addition to the rounded magnetic anomaly, the heat capacity of $\mathrm{FeMoO}_{4}-\mathrm{II}$ revealed a small bump located close to $273 \mathrm{~K}$, which is believed to result from the fusion of water. The hydrothermal origin of this sample and the lack of such a bump in samples of $\alpha-\mathrm{FeMoO}_{4}$ tends to support this interpretation more than any other (e.g. magnetic impurities, etc.). From the excess enthalpy in the region of this small bump, a value of 0.0202 mass per cent of $\mathrm{H}_{2} \mathrm{O}$ was computed by making use 
TABLE 6. Enthalpy determinations of iron(II) molybdates $\left(\mathrm{cal}_{\mathrm{th}}=4.184 \mathrm{~J}\right)$

\begin{tabular}{|c|c|c|c|c|}
\hline Designation & $\frac{T_{1}}{\mathrm{~K}}$ & $\frac{T_{2}}{\mathrm{~K}}$ & $\frac{H\left(T_{2}\right)-H\left(T_{1}\right)}{\mathrm{cal}_{\mathrm{th}} \mathrm{mol}^{-1}}$ & $\frac{H(60 \mathrm{~K})-H(30 \mathrm{~K})}{\mathrm{cal}_{\mathrm{th}} \mathrm{mol}^{-1}}$ \\
\hline \multicolumn{5}{|c|}{$\mathrm{FeMoO}_{4}$-II } \\
\hline $\begin{array}{l}\text { A (Series XIV) } \\
\text { B (Series XV) } \\
\text { Series XIII }\end{array}$ & $\begin{array}{l}29.86 \\
30.40 \\
31.53\end{array}$ & $\begin{array}{l}59.93 \\
60.10 \\
53.98\end{array}$ & $\begin{array}{l}162.078 \\
161.588 \\
123.717\end{array}$ & $\begin{array}{l}162.147 \\
162.048 \\
161.965\end{array}$ \\
\hline \multicolumn{5}{|c|}{ Average: $162.053 \pm 0.06$} \\
\hline \multicolumn{5}{|c|}{$\begin{array}{c}\alpha-\mathrm{FeMoO}_{4} \\
\text { (Bureau of Mines Sample) }\end{array}$} \\
\hline $\begin{array}{l}\text { A (Series VI) } \\
\text { B (Series VI) } \\
\text { C (Series VIII) } \\
\text { Series V }\end{array}$ & $\begin{array}{l}25.23 \\
28.23 \\
24.27 \\
24.27\end{array}$ & $\begin{array}{l}38.03 \\
39.42 \\
39.10 \\
35.38\end{array}$ & $\begin{array}{l}48.623 \\
43.605 \\
55.405 \\
41.309\end{array}$ & $\begin{array}{l}55.803 \\
55.848 \\
55.711 \\
55.763\end{array}$ \\
\hline \multicolumn{5}{|c|}{ Average: $55.781 \pm 0.06$} \\
\hline
\end{tabular}

TABLE 7. Experimental heat capacities of alpha-iron(II) molybdates $\left(\mathrm{cal}_{\mathrm{th}}=4.184 \mathrm{~J}\right)$

\begin{tabular}{|c|c|c|c|c|c|c|c|}
\hline$\frac{T}{\bar{K}}$ & $\frac{C_{p}}{\mathrm{Cal}_{\mathrm{th}} \mathrm{K}^{-1} \mathrm{~mol}^{-1}}$ & $\frac{T}{\mathbf{K}}$ & $\frac{C_{p}}{\mathrm{Cal}_{\mathrm{th}} \mathrm{K}^{-1} \mathrm{~mol}^{-1}}$ & $\frac{T}{\mathrm{~K}}$ & $\frac{C_{p}}{\mathrm{cal}_{\text {th }} \mathrm{K}^{-1} \mathrm{~mol}^{-1}}$ & $\frac{T}{\mathrm{~K}}$ & $\frac{C_{p}}{\mathrm{cal}_{\mathrm{th}} \mathrm{K}^{-1} \mathrm{~mol}^{-1}}$ \\
\hline \multicolumn{8}{|c|}{ Dupont Sample } \\
\hline & Series I & 156.19 & 19.41 & 339.78 & 30.04 & 12.44 & 0.659 \\
\hline 250.77 & $\begin{array}{l}7 \quad 26.27\end{array}$ & 163.86 & 20.14 & 347.03 & 30.35 & 15.67 & 0.869 \\
\hline 259.61 & 26.71 & 172.04 & 20.85 & & & 18.76 & 1.351 \\
\hline 268.33 & 27.12 & 180.76 & 21.58 & \multirow{2}{*}{\multicolumn{2}{|c|}{ Series IV a }} & 21.21 & 1.850 \\
\hline 276.93 & 27.56 & 189.34 & 22.24 & & & 23.41 & 2.394 \\
\hline 286.05 & 27.96 & 198.69 & 22.94 & 5.79 & 0.061 & 25.61 & 3.106 \\
\hline 296.06 & 28.44 & 205.84 & 23.48 & 6.26 & 0.097 & 28.24 & 4.118 \\
\hline 307.60 & 28.92 & 214.40 & 24.04 & 7.76 & 0.189 & 32.13 & 4.366 \\
\hline 319.91 & 29.42 & 223.38 & 24.62 & 8.44 & 0.285 & 37.02 & 3.971 \\
\hline 332.05 & 29.88 & 232.38 & 25.16 & 8.95 & 0.226 & 41.53 & 4.355 \\
\hline & & 241.40 & 25.69 & $\begin{array}{r}9.64 \\
1015\end{array}$ & 0.300 & 45.99 & 4.910 \\
\hline \multicolumn{2}{|c|}{ Series II } & & & $\begin{array}{l}10.15 \\
1082\end{array}$ & $\begin{array}{l}0.309 \\
0.437\end{array}$ & 51.16 & 5.631 \\
\hline 69.24 & $4 \quad 8.356$ & \multirow{2}{*}{\multicolumn{2}{|c|}{ Series III }} & 11.60 & 0.646 & & \\
\hline 73.45 & 8.963 & & & 12.87 & 0.686 & \multirow{2}{*}{\multicolumn{2}{|c|}{ Series VI }} \\
\hline 79.38 & 9.887 & 248.46 & 26.10 & 14.94 & 0.780 & & \\
\hline 86.39 & 10.97 & 257.68 & 26.62 & 1609 & 1062 & 56.75 & 6.439 \\
\hline 94.25 & 12.09 & 266.99 & 27.11 & 16.99 & 1.062 & 62.54 & 7.325 \\
\hline 102.12 & 13.15 & 276.34 & 27.57 & 18.87 & 1.374 & 68.43 & 8.214 \\
\hline 109.41 & 14.12 & 285.79 & 27.99 & 20.86 & $1.7 / 3$ & 74.77 & 9.166 \\
\hline 116.93 & 15.08 & 295.39 & 28.41 & & & 82.28 & 10.38 \\
\hline 124.75 & 16.04 & 314.91 & 29.19 & & Series $V^{a}$ & 90.90 & 11.50 \\
\hline 132.20 & 16.91 & 324.36 & 29.50 & 6.44 & 0.095 & 98.23 & 12.62 \\
\hline 148.26 & 18.64 & 332.51 & 29.93 & 9.44 & 0.293 & 107.48 & 13.86 \\
\hline
\end{tabular}


TABLE 7-(continued)

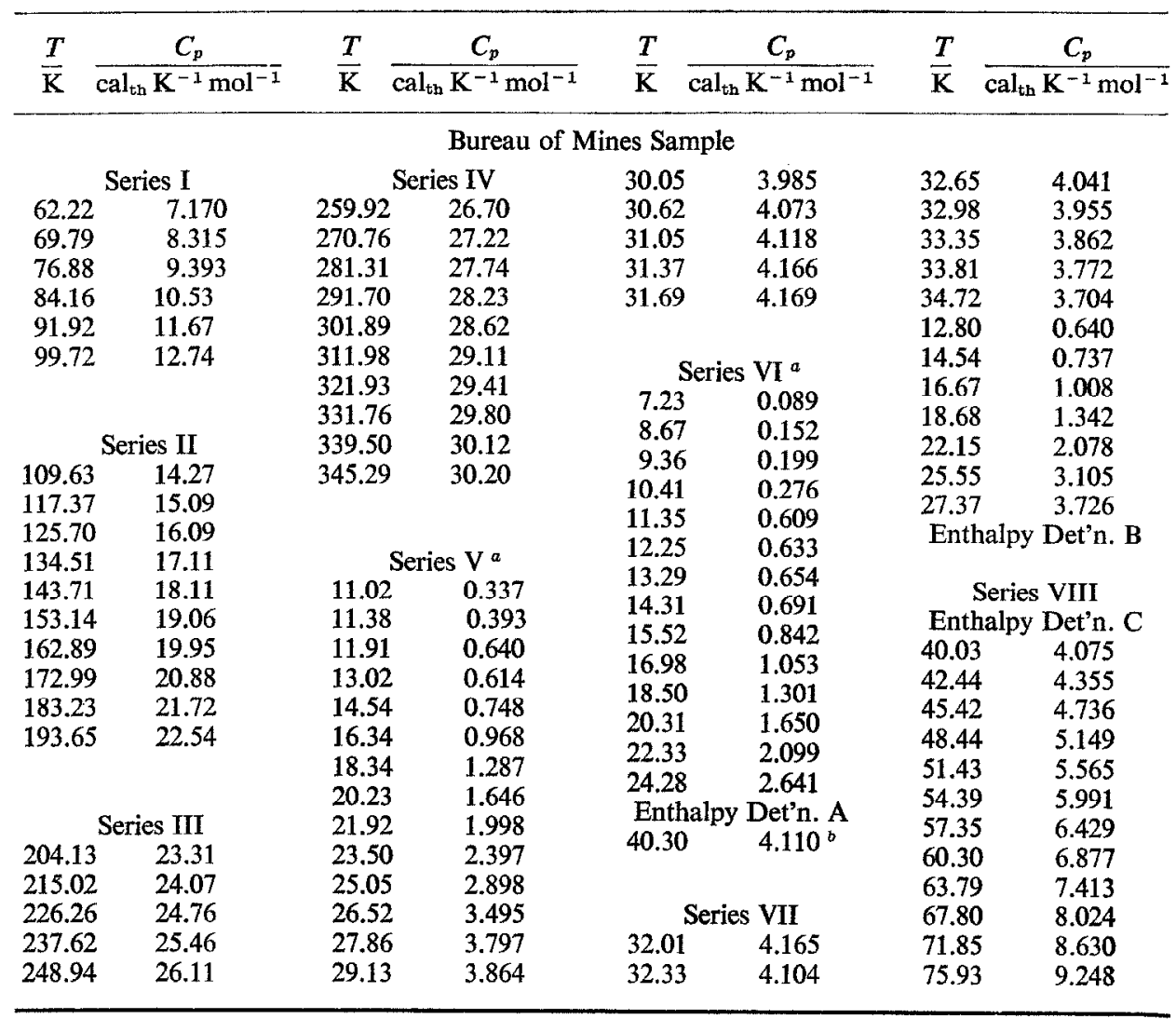

${ }^{a}$ These series were not curvature corrected. ${ }^{(15)}$

${ }^{b}$ Curvature corrected.

of the value, $143.63 \mathrm{cal}_{\mathrm{th}} \mathrm{mol}^{-1}$, for the enthalpy of fusion of pure water given in Circular $500 .^{(26)}$

Heat capacity of $\alpha-\mathrm{FeMoO}_{4}$. The heat capacities of the two samples of $\alpha-\mathrm{FeMoO}_{4}$ show rounded bumps located at $(30.5 \pm 0.1)$ and $(31.75 \pm 0.1) \mathrm{K}$ (in the total heat capacities) for the Dupont and Bureau of Mines samples, respectively. The anomaly for the Bureau of Mines sample showed a slight shoulder at temperatures just below the peak minimum. In the region of the rounded anomaly and at higher temperatures, the Dupont sample has a slightly higher heat capacity than the Bureau of Mines sample. Below $20 \mathrm{~K}$, the heat capacities of both samples are nearly identical. At temperatures between 12 and $13 \mathrm{~K}$ both samples exhibited a small additional bump for which it was found difficult to make consistent sets of measurements. The small size of the anomaly and the uncertainty in the results in this region, made it difficult to determine the shape of this anomaly; however, it appears to be a very small finite peak rather than a sharp discontinuity. 


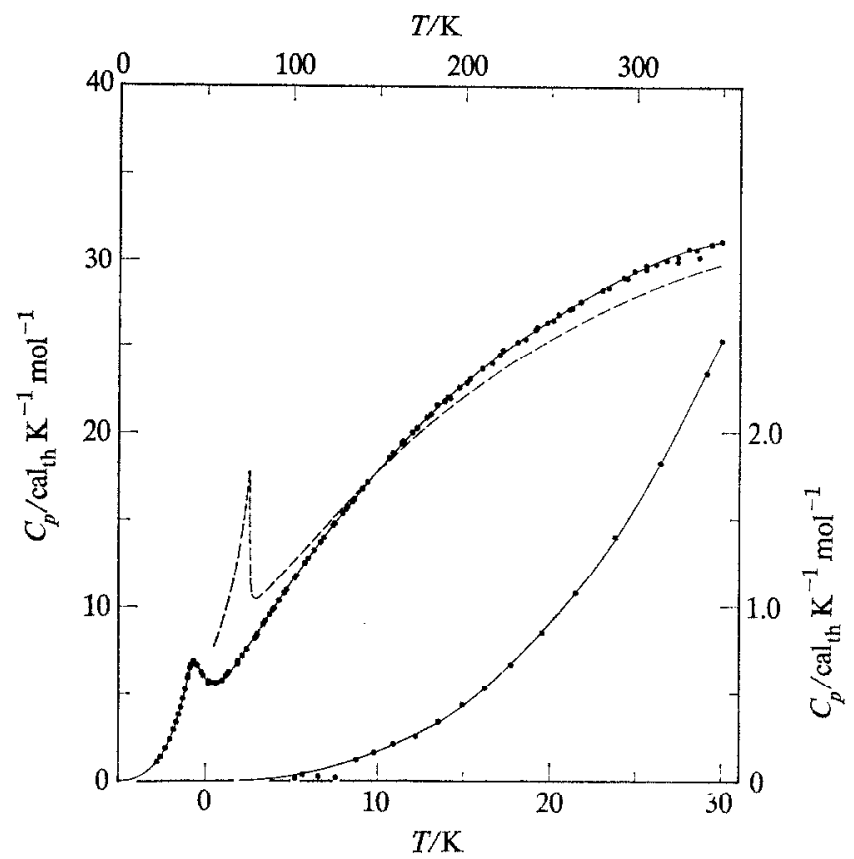

FIGURE 1. Heat capacity of $\mathrm{FeMoO}_{4}$-II.

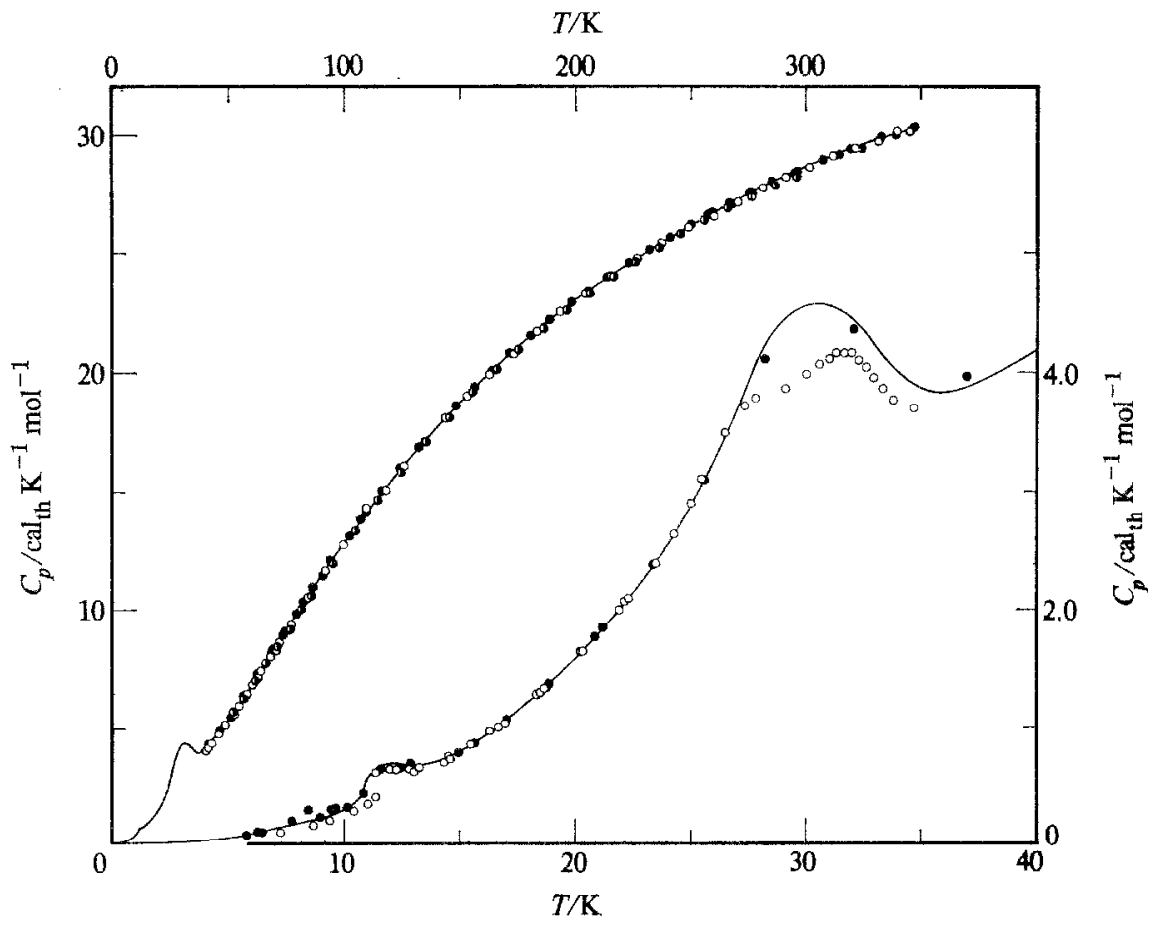

FIGURE 2. Heat capacity of $\alpha-\mathrm{FeMoO}_{4} . \bullet$, this work, Dupont samplc; $\bigcirc$, this work, Burcau of Mines sample; $\mathbf{D}$, Weller; $;^{(12)} \longrightarrow$, results for Dupont sample. 


\section{CALCULATIONS}

Impurity corrections. Adjustment for the small amount of the water in the sample of FeMoO$-\mathrm{Il}$ was made on the experimental heat capacity by the use of the heat capacity of pure water determined by Giauque and Stout. ${ }^{(27)}$ These corrections have been made on all results given in table 5, with the exception of the two points at the peak of the water fusion bump. These latter points have only their temperature listed.

No corrections were attempted for the separate oxidation products present in the samples of ferrous molybdate. The data in table 5 through 7 are, therefore, the apparent molar heat capacities of the three samples, calculated as if they were free of oxidation products.

Thermal functions. The experimental heat capacities for the non-transition regions were curve-fitted to polynomials in reduced temperature by the method of leastsquares and then integrated to yield values of the thermal functions at regular temperature intervals. The thermal functions in the transition regions are based on enthalpy determinations covering the transition maxima and on numerical integration of heat capacities read from large scale plots of the transition regions. At temperatures below the low temperature limit of the measurements, entropy and enthalpy increments were obtained from plots of $C_{p} / T$ against $T^{2}$. No attempt was made in the process of extrapolation to adjust for contributions due to isotopic mixing or nuclear spin; hence, the values tabulated are practical values of the thermal functions for use in ordinary thermochemical calculations.

TABLE 8. Thermal functions of iron(II) molybdate-II $\left(\mathrm{cal}_{\text {th }}=4.184 \mathrm{~J}\right)$

\begin{tabular}{|c|c|c|c|c|}
\hline$\frac{T}{\mathrm{~K}}$ & $\frac{C_{p}}{\mathrm{cal}_{\mathrm{th}} \mathrm{K}^{-1} \mathrm{~mol}^{-1}}$ & $\frac{\left\{S^{\circ}(T)-S^{\circ}(0)\right\}}{\mathrm{cal}_{\mathrm{th}} \mathrm{K}^{-1} \mathrm{~mol}^{-1}}$ & $\frac{\left\{H^{\circ}(T)-H^{\circ}(0)\right\}}{\mathrm{cal}_{\mathrm{tn}} \mathrm{K}^{-1}} \frac{\mathrm{mol}^{-1}}{}$ & $\frac{-\left\{G^{\circ}(T)-H^{\circ}(0)\right\} / T}{\mathrm{cal}_{\mathrm{tn}} \mathrm{K}^{-1}} \frac{\mathrm{mol}^{-1}}{}$ \\
\hline 25 & 1.578 & 0.622 & 11.194 & 0.174 \\
\hline 50 & 5.862 & 3.579 & 126.66 & 1.026 \\
\hline 75 & 7.719 & 6.109 & 284.43 & 2.317 \\
\hline 100 & 11.385 & 8.834 & 523.4 & 3.600 \\
\hline 150 & 17.83 & 14.712 & 1259.2 & 6.318 \\
\hline 200 & 22.73 & 20.55 & 2280.3 & 9.152 \\
\hline 250 & 26.41 & 26.03 & 3511.9 & 11.987 \\
\hline 298.15 & 29.05 & 30.93 & 4852.3 & 14.656 \\
\hline 300 & 29.13 & 31.11 & 4906.1 & 14.757 \\
\hline 350 & 31.19 & 35.76 & 6415 & 17.43 \\
\hline
\end{tabular}

Values of the thermal functions for $\mathrm{FeMoO}_{4}$-II are presented in an abbreviated form in table 8 and in the usual manner in the supplementary document. (15) Selection of a suitable composite set of thermal functions for $\alpha-\mathrm{FeMoO}_{4}$ has proven problematical; however, table 9 compares heat capacity, enthalpy, and entropy increments from this research and that of Weller. ${ }^{(12)}$ 
TABLE 9. Comparison of the thermal functions of $\alpha$-ferrous molybdate samples $\left(\mathrm{cal}_{\mathrm{th}}=4.184 \mathrm{~J}\right)$

\begin{tabular}{|c|c|c|c|}
\hline & Dupont & Burcau of Mines & Weller ${ }^{a}$ \\
\hline$T / \mathrm{K}$ & \multicolumn{3}{|c|}{$C_{p} / \mathrm{cal}_{\mathrm{th}} \mathrm{K}^{-1} \mathrm{~mol}^{-1}$} \\
\hline 50 & 5.47 & 5.37 & 5.31 \\
\hline 75 & 9.22 & 9.12 & 9.11 \\
\hline 100 & 12.89 & 12.80 & 12.71 \\
\hline 150 & 18.78 & 18.74 & 18.67 \\
\hline 200 & 23.06 & 23.00 & 22.93 \\
\hline 250 & 26.25 & 26.17 & 26.08 \\
\hline 298.15 & 28.52 & 28.48 & 28.31 \\
\hline 300 & 28.60 & 28.56 & - \\
\hline 350 & 30.43 & 30.40 & - \\
\hline$\left\{H^{\circ}(50 \mathrm{~K})-H^{\circ}(0)\right\} / \mathrm{cal}_{\mathrm{th}} \mathrm{mol}^{-1}$ & 128.66 & 124.20 & $(84.28)^{b}$ \\
\hline$\left\{H^{\circ}(298.15 \mathrm{~K})-H^{\circ}(50 \mathrm{~K})\right\} / \mathrm{cal}_{\mathrm{th}} \mathrm{mol}^{-1}$ & 4870 & 4853 & 4834 \\
\hline$\left\{H^{\circ}(298.15 \mathrm{~K})-H^{\circ}(0)\right\} / \mathrm{cal}_{\mathrm{ln}} \mathrm{mol}^{-1}$ & 4998 & 4977 & (4918) \\
\hline$S^{\circ}(50 \mathrm{~K}) / \mathrm{cal}_{\mathrm{th}} \mathrm{K}^{-1} \mathrm{~mol}^{-1}$ & 4.08 & 3.94 & $(2.31)^{b}$ \\
\hline$\left\{S^{\circ}(298.15 \mathrm{~K})-S^{\circ}(50 \mathrm{~K})\right\} / \mathrm{cal}_{t \mathrm{~h}} \mathrm{~K}^{-1} \mathrm{~mol}^{-1}$ & 28.84 & 28.70 & 28.60 \\
\hline$S^{\circ}(298.15 \mathrm{~K}) / \mathrm{cal}_{\mathrm{th}} \mathrm{K}^{-1} \mathrm{~mol}^{-1}$ & 32.92 & 32.64 & (30.91) \\
\hline \multicolumn{4}{|c|}{ Provisional thermal functions at $T=298.15 \mathrm{~K}^{\circ}$} \\
\hline$C_{\mathfrak{p}}^{\circ} / \mathrm{cal}_{\mathrm{th}} \mathrm{K}^{-1} \mathrm{~mol}^{-1}=28.31$ & $\multicolumn{3}{|c|}{H^{\circ}(T)-H^{\circ}(0)} / \mathrm{cal}_{\mathrm{th}} \mathrm{mol}^{-1}=4963$ \\
\hline$S^{\circ} / \mathrm{cal}_{\mathrm{th}} \mathrm{K}^{-1} \mathrm{~mol}^{-1}=(32.7 \pm 0.1)$ & \multicolumn{3}{|c|}{$-\left\{G^{\circ}(T)-H^{\circ}(0)\right\} T^{-1} / \mathrm{cal}_{\mathrm{th}} \mathrm{K}^{-1} \mathrm{~mol}^{-1}=16.1$} \\
\hline
\end{tabular}

a Reanalyzed Weller ${ }^{(12)}$ results on Bureau of Mines sample.

${ }^{b}$ The parenthetic values represent smooth extrapolations made on the basis of the representation of the heat capacity in the 50 to $298.15 \mathrm{~K}$ range as a combination of Debye and Einstein functions given by Weller. ${ }^{(12)}$ Such an extrapolation obviously neglects the possibility of a transition below $50 \mathrm{~K}$.

c The selected values are a combination of the results from the Dupont sample below $50 \mathrm{~K}$, and of the results from Weller's sample from 50 to $298.15 \mathrm{~K}$.

The thermal functions for all three samples of iron(II) molybdate are considered to have a precision corresponding to a probable error of less than 0.1 per cent above $100 \mathrm{~K}$.

\section{Discussion}

\section{MAGNETIC CONTRIBUTIONS TO THE HEAT CAPACITY}

\section{$\mathrm{FeMoO}_{4}-\mathrm{II}$}

The temperature, $(43.0 \pm 0.1) \mathrm{K}$, of the peak maximum in the (total) heat capacity correlates well with the temperature, $(45 \pm 5) \mathrm{K}$, of the maximum in magnetic susceptibility determined by Sleight et al. ${ }^{(7)}$ However, the rounded character of the observed anomaly is different from the usual sharp "lambda" shape ordinarily associated with the onset of magnetic ordering ( $c f$. Stout $\left.{ }^{(28)}\right)$.

Some insight into the problem of analyzing the magnetic contribution to the heat capacity for $\mathrm{FeMoO}_{4}$-II may be obtained from an examination of figure 1 which 
contrasts the heat capacities of $\mathrm{FeMoO}_{4}-\mathrm{II}$ and $\mathrm{FeWO}_{4}$. In view of the fact that these two materials are roughly iso-structural, the differences are quite remarkable. Most notable is the fact that the heat capacity of $\mathrm{FeMoO}_{4}$-II greatly exceeds that of $\mathrm{FeWO}_{4}$ in the region above $200 \mathrm{~K}$, despite the fact that the molar mass of the latter compound is considerably greater (by a factor of about 1.4) than that of the former. While it is not necessarily unusual for the heat capacities of molybdenum compounds to exceed those of the analogous tungsten compounds (cf. King et al. ${ }^{(29)}$ for a comparison of the compounds, $\mathrm{MoO}_{3}, \mathrm{WO}_{3}, \mathrm{MoO}_{2}$, and $\mathrm{WO}_{2}$ ) such an effect practically annihilates any hope of analyzing the lattice heat capacity of $\mathrm{FeMoO}_{4}$-II through adjustment of the heat capacity of an iso-structural tungstate. Large differences in heat capacity could arise from a combination of differences in lattice dynamics and in electronic contributions to the heat capacity; the analysis of the relative importance of these two possibilities would require heat capacities for $\mathrm{ZnMoO}_{4}$-II.

The transition region of $\mathrm{FeMoO}_{4}-\mathrm{II}$ is depicted in detail in figure 3 with a splined interpolation of the lattice heat capacity. The lattice estimate selected here is a

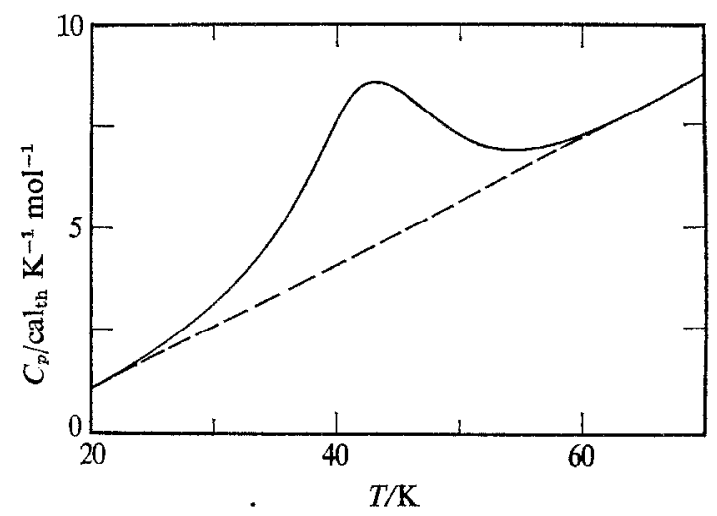

FIGURE 3. Heat capacity of $\mathrm{FeMoO}_{4}-\mathrm{II}$ in the transition region. —_, experimental; - - - , estimated lattice heat capacity.

maximal one; i.e. the chosen curve is a smooth extrapolation under the obviously anomalous region, and thus may tend to under-estimate the magnetic heat capacities in both the spin-wave and the short-range ordering regions. Based on this lattice, the excess enthalpy and entropy associated with the anomaly are $46.2 \mathrm{cal}_{\mathrm{th}} \mathrm{mol}^{-1}$ and $1.11 \mathrm{cal}_{\mathrm{th}} \mathrm{K}^{-1} \mathrm{~mol}^{-1}$, respectively.

Such a value for the excess entropy is rather surprising. Transitions with excess entropies near $R \ln 2$ have been observed previously for iron(II) compounds [e.g. $\mathrm{FeCl}_{2}{ }^{(28)}$ and $\left.\mathrm{FeCO}_{3}{ }^{(30)}\right]$; however, in these instances the site symmetry of the $\mathrm{Fe}^{2+}$ ions is higher $\left(\mathrm{D}_{3 \mathrm{~d}}\right)$, and the entropies appear to be a reasonable consequence of the pattern of crystal field splitting ( $c f$. Kanamori $\left.{ }^{(31)}\right)$. In $\mathrm{FeMoO}_{4}$-II, the triclinic symmetry of the crystal would suggest that the pattern of energy levels should be similar to $\mathrm{FeWO}_{4}$. Indeed, the quadruple splittings derived by Sleight $e t$ al. ${ }^{(7)}$ from Mössbauer spectra at 4.2, 78, and $297 \mathrm{~K}$ show so little temperature variation that 
low-lying electronic energy levels seem ruled out. ${ }^{(32)}$ Nevertheless, the possibility remains that a ground-state doublet separated by many hundreds $\mathrm{of}^{-1}$ from the excited states exists here.

An alternate possibility is that sample impurities and/or poor choice of lattice heat capacity has misled these authors to a value of the excess entropy, only one-third of $R \ln 5$. The anomaly depicted in figure 3 is remarkable for the high degree of symmetry exhibited near the peak of the transition. The nearly Gaussian shape of the excess heat capacity occasions some concern over the true extent of the anomaly on the high-temperature side. Since the total entropy of $\mathrm{FeMoO}_{4}-\mathrm{II}$ at $50 \mathrm{~K}$ barely exceeds $R \ln 5$, the region of short-range ordering in $\mathrm{FeMoO}_{4}-\mathrm{II}$ would have to be remarkably large to achieve the excess entropy of $R \ln 5$ that might be expected from magnetic ordering analogous to that in $\mathrm{FeWO}_{4}$. Although a more secure basis for estimating the lattice heat capacity would be required to rule out the latter possibility with assurance, an excess entropy as large as $R \ln 5$ would be possible if the impurities have a disproportionately large effect on the transition.

$\alpha-\mathrm{FeMoO}_{4}$

The transition regions for both samples of $\alpha-\mathrm{FeMoO}$ are depicted in figure 4 . The temperatures of the peak maxima for the large anomalies, $(30.5 \pm 0.1)$ and $(31.75 \pm 0.1) \mathrm{K}$, for the Dupont and Bureau of Mines samples, respectively, correlate

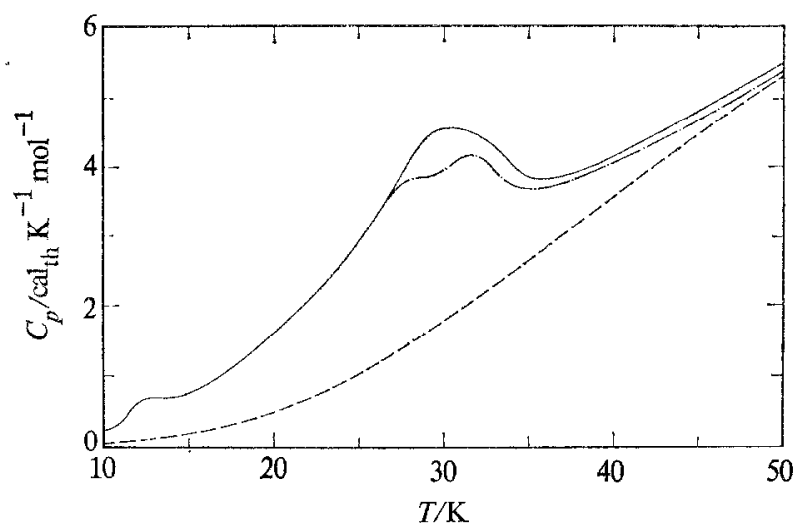

FIGURE 4. Heat capacity of $\alpha-\mathrm{HeMoO}_{4}$ in the transition region. - $\longrightarrow$, experimental, Dupont Dupont sample;-_- - - , experimental, Bureau of Mines sample; ----, estimated.

well with the maximum, at a temperature of $(30 \pm 5) \mathrm{K}$, in magnetic susceptibility observed by Sleight $e t a l .{ }^{(7)}$ but not identified as the onset of magnetic ordering. Whatever the origin of the peculiar magnetic behavior, it is clear from the present heat capacities that $\alpha-\mathrm{FeMoO}$ shows very complex behavior below $50 \mathrm{~K}$, and that (at least) two bumps appear in the heat capacity. The small anomalies, appearing at 12 to $13 \mathrm{~K}$ in the heat capacities of both samples, are either non-magnetic in origin, or else of sufficiently small size so that the effect escaped detection in the magnetic-susceptibility measurements. 
Estimating the lattice heat capacity throughout the anomalous region is here further complicated by the overlapping of two transition regions. No attempt will be made in this analysis to resolve separately the excess entropies of these two transitions.

Use of Weller's ${ }^{(12)}$ smooth extrapolation of the heat capacity of $\alpha-\mathrm{FeMoO}_{4}$ (in Debye and Einstein functions) as a lattice heat capacity, results in values of the excess entropy of 1.77 and $1.63 \mathrm{cal}_{\mathrm{th}} \mathrm{K}^{-1} \mathrm{~mol}^{-1}$ associated with the entire anomalous regions of the Dupont and Bureau of Mines samples, respectively. In these cases also, the relatively low values of the excess entropy seem rather surprising in view of the low site symmetry of the $\mathrm{Fe}^{2+}$ ions.

The crystal structure of $\alpha-\mathrm{FeMoO}_{4}$ permits two different kinds of sites for the $\mathrm{Fe}^{2+}$ ions (mirror planes or diagonal axes); however, the environments of the two kinds of $\mathrm{Fe}^{2+}$ ions must be very similar, since the room temperature Mössbauer spectrum of Sleight et al. ${ }^{(7)}$ failed to distinguish them. At a temperature of $4.2 \mathrm{~K}$, the Mössbauer spectrum-while not showing a clear-cut magnetic hyperfine pattern -does show quadruple-split absorption peaks consistent with two different iron sites. The strong variation of the quadruple splittings computed by these authors from the spectra at $4.2,78,246$, and $297 \mathrm{~K}$ seems strongly indicative of very low-lying energy levels ( $c f$. Ingalls ${ }^{(32)}$ ).

The present heat-capacity results, which clearly indicate an extensive cooperative anomaly at temperatures below $50 \mathrm{~K}$, tend to support the contention that some kind of magnetic ordering is taking place. Possibly the small transition at 12 to $13 \mathrm{~K}$ is associated with a volume distortion or alteration of magnetic structure sufficient to render the two types of $\mathrm{Fe}^{2+}$ ions distinguishable in the Mössbauer spectrum at $4.2 \mathrm{~K}$. To be completely consistent with the Mössbauer results at $4.2 \mathrm{~K}$, the process of magnetic ordering would have to result, according to Sleight et al., ${ }^{(7)}$ in effective internal magnetic fields about ten times smaller than usually observed for iron(II) compounds. A more detailed examination of Mössbauer spectra as a function of temperature throughout the anomalous region should prove useful in resolving this apparent conflict. If, indeed, the effective internal fields are of so small a magnitide, it may be possible to induce ferromagnetism in this material by applying relatively small external magnetic fields; such experiments would provide a further test of the explanation favored by us.

\section{EFFECTS OF IMPURITIES}

In non-transition regions, various calculations of the effects of the impurities present as separate phases in these $\mathrm{FeMoO}_{4}$ samples indicate that apparent heat capacities would be only slightly increased over true heat capacities ${ }^{(15)}$ (up to 0.7 per cent). These calculations are in good accord with the measured heat-capacity spread of $\alpha-\mathrm{FeMoO}_{4}$.

In the transition region, however, the direct effect of separate phase impurities is more serious. On the assumption that the mass fraction of $\mathrm{FeMoO}_{4}$ at the time of the heat capacity measurement was 0.77 or greater, the excess entropy of the magnetic anomaly in the $\mathrm{FeMoO}_{4}$-II sample may be adjusted to a value of $1.44 \mathrm{cal}_{\text {th }} \mathrm{K}^{-1} \mathrm{~mol}^{-1}$; hence, it is unlikely that separate phase impurities alone would account for an apparent 
excess entropy so much less than $R \ln 5\left(3.20 \mathrm{cal}_{\mathrm{th}} \mathrm{K}^{-1} \mathrm{~mol}^{-1}\right)$. The assumption of similar levels of separate phase contaminants for the samples of $\alpha-\mathrm{FeMoO}_{4}$ at the time of heat capacity measurement would yield adjusted values of $2.30 \mathrm{cal}_{\mathrm{th}} \mathrm{K}^{-1} \mathrm{~mol}^{-1}$ and $2.12 \mathrm{cal}_{\mathrm{th}} \mathrm{K}^{-1} \mathrm{~mol}^{-1}$, respectively, for the excess entropies of the Dupont and Bureau of Mines samples. Here too, it is unlikely that separate phase impurities alone could account for an apparent excess entropy so much less than $R \ln 5$; however, an entropy greater than $R \ln 2$ seems indicated.

The rounding of heat-capacity peaks because of hidden variables is not a well understood subject either theoretically ${ }^{(33)}$ or empirically. ${ }^{(15)}$ Within the precision of the X-ray characterization, no deviations of lattice parameters indicative of solid solution (e.g. of $\mathrm{Fe}^{3+}$ ions) were noted. Hence, the probable cause of rounding in these samples is not supported by direct evidence. Because of the possibility of a disproportionate effect for this type of impurity on the excess entropy, the present conclusions are somewhat guarded.

We thank Dr E. G. King of the Albany Metallurgy Research Center, U.S. Bureau of Mines, Albany, Oregon for the loan of a sample of $\alpha-\mathrm{FeMoO}_{4}$, and $\mathrm{Dr} \mathrm{A}$. W. Sleight of the Central Research Department of E. I. du Pont de Nemours and Company, Wilmington, Delaware, for samples of $\alpha-\mathrm{FeMoO}_{4}$ and $\mathrm{FeMoO}_{4}$-II. P. F. Finamore and K. Gerst assisted with many of the experimental measurements and calculations. Assistant Professor J. Haschke of the Department of Chemistry, The University of Michigan, gave much valuable advice and assistance with the $\mathrm{X}$-ray measurements and calculations.

\section{REFERENCES}

1. Brenner, S. S. J. Electrochem. Soc. 1955, $102,7$.

2. Rahmcl, A.; Jägcr, W.; Becker, K. Arch. Eisenhuttenw. 1959, 30, 351.

3. Van Uitert, L. G.; Swanekamp, F. W.; Preziosi, S. J. Appl. Phys. 1961, 32, 1176.

4. Palache, C.; Berman, H.; Frondel, C. Dana's System of Minerology, Vol. II. Seventh Edition. John Wiley and Sons, Inc.: New York. 1951, pp. 1079-86.

5. Urosov, V. S.; Ivanova, G. F.; Khodakovskii, I. L. Geokhimiya 1967, 1050.

6. Sleight, A. W.; Chamberland, B. L. Inorg. Chem. 1968, 7, 1672.

7. Sleight, A. W.; Chamberland, B. L.; Weiher, J. F. Inorg. Chem. 1968, 7, 1093.

8. Smith, G. W.; Ibers, J. S. Acta Cryst. 1965, 19, 269.

9. Young, A. P.; Schwartz, C. M. Science 1963, 141, 348.

10. Marshall, D. J. J. Mater. Sci. 1967, 2, 294.

11. Keeling, R. O. Acta Cryst. 1957, 10, 209.

12. Weller W. W. U.S. Bur. Mines, Rep. Invest. 6782, 1966.

13. Lyon, W. G.; Westrum, E. F., Jr. J. Chem. Thermodynamics 1974, 6, 763.

14. Lyon, W. G., Ph.D. Thesis, The University of Michigan, Ann Arbor, Michigan, 1973. Diss. Abst., 1975, 35, Issue 1, 75-15790.

15. Detailed supplementary data concerning X-ray and chemical analyses of the samples used in this research, see NAPS document No. 02553 for 29 pages of supplementary material. Order from ASIS/NAPS, c/o Microfiche Publications, 305 E. 46th St., New York, N.Y. 10017. Remit in advance for each NAPS accession number. Make checks payable to Microfiche Publications. Photocopies are \$5.00. Microfiche are \$1.50. Outside of the U.S. or Canada, postage is $\$ 2.00$ for a PC or $\$ 0,50$ for a fiche.

16. Joint Committee on Powder Difraction Standards, Inc., 1601 Park Lane, Swarthmore, PA. Card \#13-0534.

17. Sleight, A. W.; personal communication.

18. Nassau, K.: Levinstein, H. J.; Loicono, G. M. J. Phys. Chem. Solids 1965, 26, 1805. 
19. Trunov, V. K.; Kovba, L. M. Izv. Akad. Nauk SSSR, Neorgan. Mater. 1966, $2,151$.

20. Plyasova, L. M.; Klevtsova, R. F.; Borisov, S. V.; Kefeli, L. M. Dokl. Akad. Nauk SSSR 1965, 167, 84. (Cf. Soviet Physics-Doklady 1966, 11, 189.)

21. Klevtsov, P. V.; Kefeli, L. M.; Plyasova, L. M. Izv. Akad. Nauk SSSR, Neorgan. Mater. 1965, 1,918 .

22. Sleight, A. W.; Brixner, L. H. J. Solid State Chem. 1973, 7, 172.

23. Kozmanov, Yu. D. Zh. Fiz. Khim. 1957, 31, 1861.

24. Jäger, W.; Rahmel, A.; Becker, K. Arch. Eisenhuttenw. 1959, 30, 435.

25. Westrum, E. F., Jr.; Furukawa, G. T.; McCullough, J. P. Adiabatic low-temperature calorimetry. Chap. 5 in Experimental Thermodynamics, Vol. I. McCullough, J. P.; Scott, D. W.; editors. Butterworths: London. 1968, p. 133.

26. Rossini, F. D.; Wagman, D. D.; Evans, W. H.; Levine, S.; Jaffe, I. National Bureau of Standards Circular No. 500. U.S. Government Printing Office, Washington, D.C. 1952.

27. Giauque, W. F.; Stout, J. W. J. Amer. Chem. Soc. 1939, 58, 1144.

28. Stout, J. W. Pure Appl. Chem. 1961, 2, 287.

29. King, E. G.; Weller, W. W.; Christensen, A.U. U.S. Bur. Mines Rep. Invest. 5664, 1960.

30. Kalinkina, I. N. Zh. Eksperim. i Teor. Fiz. 1962, 43, 2028. (Cf. Soviet Physics-JETP 1963, $16,1432$.

31. Kanamori, J. Progr. Theoret. Phys. (Japan) 1958, $20,890$.

32. Ingalls, R. Phys. Rev. 1964, 133, A787.

33. Fisher, M. E. Phys. Rev. 1968, 176, 257. 